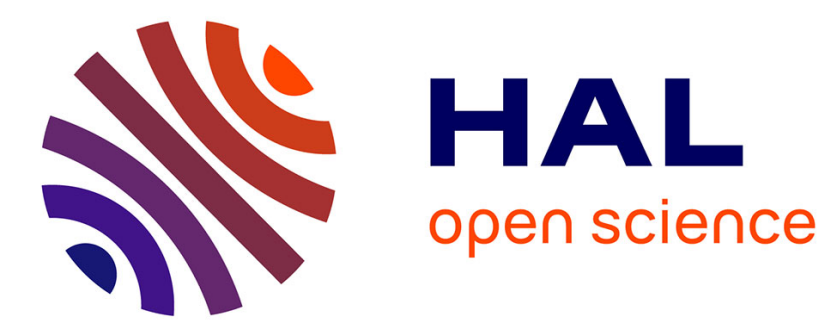

\title{
Evaluation of Indirect Fluorescent Antibody Test (IFAT) for the Diagnosis and Screening of Lumpy Skin Disease Using Bayesian Method
}

G. Gari, F. Biteau-Coroller, C. Legoff, P. Caufour, F. Roger

\section{- To cite this version:}

G. Gari, F. Biteau-Coroller, C. Legoff, P. Caufour, F. Roger. Evaluation of Indirect Fluorescent Antibody Test (IFAT) for the Diagnosis and Screening of Lumpy Skin Disease Using Bayesian Method. Veterinary Microbiology, 2008, 129 (3-4), pp.269. 10.1016/j.vetmic.2007.12.005 . hal-00532374

\section{HAL Id: hal-00532374 \\ https://hal.science/hal-00532374}

Submitted on 4 Nov 2010

HAL is a multi-disciplinary open access archive for the deposit and dissemination of scientific research documents, whether they are published or not. The documents may come from teaching and research institutions in France or abroad, or from public or private research centers.
L'archive ouverte pluridisciplinaire HAL, est destinée au dépôt et à la diffusion de documents scientifiques de niveau recherche, publiés ou non, émanant des établissements d'enseignement et de recherche français ou étrangers, des laboratoires publics ou privés. 


\section{Accepted Manuscript}

Title: Evaluation of Indirect Fluorescent Antibody Test (IFAT) for the Diagnosis and Screening of Lumpy Skin Disease Using Bayesian Method

Authors: G. Gari, F. Biteau-Coroller, C. LeGoff, P. Caufour, F. Roger

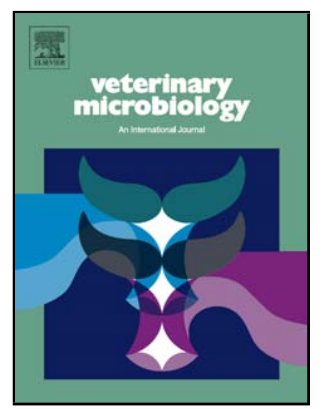

PII: S0378-1135(07)00616-5

DOI: doi:10.1016/j.vetmic.2007.12.005

Reference: VETMIC 3915

To appear in: $\quad$ VETMIC

Received date: $\quad 11-10-2007$

Revised date: 28-11-2007

Accepted date: $\quad$ 5-12-2007

Please cite this article as: Gari, G., Biteau-Coroller, F., LeGoff, C., Caufour, P., Roger, F., Evaluation of Indirect Fluorescent Antibody Test (IFAT) for the Diagnosis and Screening of Lumpy Skin Disease Using Bayesian Method, Veterinary Microbiology (2007), doi:10.1016/j.vetmic.2007.12.005

This is a PDF file of an unedited manuscript that has been accepted for publication. As a service to our customers we are providing this early version of the manuscript. The manuscript will undergo copyediting, typesetting, and review of the resulting proof before it is published in its final form. Please note that during the production process errors may be discovered which could affect the content, and all legal disclaimers that apply to the journal pertain. 


\title{
Evaluation of Indirect Fluorescent Antibody Test (IFAT) for the Diagnosis and Screening of Lumpy Skin Disease Using Bayesian Method
}

\author{
Authors: Gari G. ${ }^{a}$, Biteau-Coroller F. ${ }^{\mathrm{b}}$, LeGoff C. ${ }^{\mathrm{c}}$, Caufour P. ${ }^{\mathrm{c}}$, Roger F $^{\mathrm{b}}$
}
a) Sebeta National Animal Health Research Center, P O Box 04, Sebeta, Ethiopia.
b) CIRAD, Epidemiology and Ecology of Animal Diseases Unit, TA A-16 / E, Campus International de Baillarguet, 34398 Montpellier Cedex 5, France.
c) CIRAD, Emerging and Exotic Animal Disease Control Unit, TA A-15 / G, Campus International de Baillarguet, 34398 Montpellier Cedex 5, France.

\begin{abstract}
The performance of Indirect Fluorescence Antibody Test (IFAT) for serological diagnosis and screening of Lumpy Skin Disease (LSD) was evaluated using methods without gold standard. Virus neutralization test (VNT) was used as the second test and the study sites were selected from two different geographical places in Ethiopia to get different disease prevalence. The analysis of conditional dependent Bayesian model for the accuracy of IFAT showed that sensitivity, specificity, prevalence of the population $\mathrm{Pi}_{1}$ and the population $\mathrm{Pi}_{2}$ were 0.92 (0.89- 0.95), 0.88 (0.85-0.91), 0.28 (0.25- 0.32) and 0.06(0.048- 0.075) respectively. The posterior inferences obtained for VNT sensitivity, specificity and conditional correlation between the tests for sensitivity (rhoD) and specificity (rhoDc) were 0.78 (0.74- 0.83), 0.97 (0.95- 0.99), 0.052 (-0.03- 0.15) and 0.019 (-0.01-0.06) respectively. The interval estimation of conditional correlation for both sensitivity and specificity clusters around zero and thus conditional dependence between the two tests was not significant. Although accuracy measure would not be the only basis for test selection, the result of our study demonstrated that IFAT has a reasonable high accuracy to be used for the diagnosis and sero-surveillance analysis of LSD in the target population.
\end{abstract}

Keywords: Bayesian model, Cattle, Ethiopia, Lumpy Skin Disease, Sensitivity, Specificity, IFAT

Corresponding Author Current Address: Getachew Gari, CIRAD, Epidemiology and Ecology of Animal Diseases Unit, TA A-16 / E, Campus International de Baillarguet, 34398 Montpellier Cedex 5, France. Email- getachew.gari@,cirad.fr, Tel- +330637130848, Fax- +33467593754 
Introduction

Lumpy skin disease (LSD) is an acute to sub acute viral disease of cattle that can cause mild to severe signs including fever, nodules in the skin, mucous membranes and internal organs, skin oedema, lymphadenitis and sometimes death. The disease causes high economic loss as a result of decreased milk production, abortion, infertility, weight loss, poor growth and skin damage (Ali et al., 1990; OIE, 2004). Lumpy skin disease is caused by the strain of Capripox virus which is genetically and antigenically close related to the strain of sheep and goat pox virus and the prototype strain is known as the Neethling Pox Virus (Alexander et al., 1957; Davies, 1982).

Currently, the distribution of LSD in Africa has increased its horizon from Sub-Saharan countries to Egypt and Western Africa countries (Davies, 1991). Davies (1991) has also emphasized that the epidemiological distribution trend of LSD has posed a considerable risk to extend its range to the Northern Africa countries and Eastern ward of the Egypt to the Middle East countries. In Ethiopia LSD was first observed in the western Ethiopia (South west of Lake Tana) in 1983 and the assumption was that it has been introduced from Sudan (Mebratu et al., 1984). The Ethiopian National Veterinary Service field report from 1999-2006 revealed that the occurrence of LSD outbreak has almost spread to all regions of the country including different agro-climatic zones. According to these reports we noted that the number of outbreaks reported per month increases highly during the wet season that is from June up to October (Ministry of Agriculture and Rural Development Disease Report Database). However, no epidemiological study has been done yet in different regions and ecotypes of the country which is indeed required to give a more realistic epidemiological picture than the one obtained by passive surveillance data.

Diagnostic and screening tests are the primary tools for successful such epidemiological study (Greiner and Gardner, 2000(a)). The OIE recommended serological tests used for LSD diagnosis are essentially IFAT (Indirect Fluorescent Antibody Test), ELISA and VNT (Virus Neutralisation Test) (OIE, 2004). Indirect ELISA of recombinant P32 antigen from KS-1 strain has been developed previously but till today it has not been validated to replace the conventional once (Heine et al., 1999). Lack of information on the performance of the available diagnostic test is also one of the limiting factors to conduct large epidemiological studies. Understanding the characteristic of the tests is essential to know how they affect the quality of data obtained from epidemiological research and can be considered as a precursor step (Dohoo et al., 2003). The accuracy of these diagnostic tests should also be evaluated for specific target 
The availability of a suitable reference test is an important requirement for the performance evaluation study. But it is difficult or sometimes next to impossible to obtain perfect (gold standard) test which can identify the true disease status of the animal (Enoe et al., 2000; Enoe et al., 2001; Dohoo et al., 2003; Biteau-Coroller et al., 2006). However, When gold standard test is not available the performance of two tests can be estimated using latent-class approaches, provided that the error probability of the reference test is known (Enoe et al., 2000). In most cases virus neutralization test (VNT) is considered as reference test which has a strong specificity but less sensitivity for capripox virus (OIE, 2004; Bhanuprakash et al., 2006).

Diagnostic test evaluation is particularly suited to the Bayesian framework (Branscum et al., 2005). The Bayesian analysis for diagnostic test evaluation without gold standard was discussed for conditional independent and conditional dependent tests (Enoe et al., 2000; Gardner et al., 2000; Johnson et al., 2001; Georgiadis et al., 2003; Branscum et al., 2005). Bayesian approach uses prior information knowledge about the parameters of the tests under study either from other similar studies or expert's best guess. Moreover, it has an advantage to provide more stable point estimates and intervals without the necessity of large sample sizes (Enoe et al., 2000). The Bayesian inference is the combination of the beta distribution of the prior information and the maximum likelihood estimates of the observed data (Gardner et al., 2000).

The objective of this study was to evaluate the performance of IFAT for diagnosis and screening of Lumpy Skin Disease in Ethiopia using VNT as second test for comparison. The Bayesian model and Hui and Walter (1980) model were used to analyse the test performance where there is no gold standard. The parameters used to measure the accuracy are sensitivity, specificity, prevalence and the conditional correlation between the two tests.

\section{Materials and Methods}

\section{Study Area and Study Population}

The study was conducted from September 2006- March 2007. Two study areas with different farming system and expected different LSD prevalence were selected. The first study area was in Amhara Region (North Wello, South Wello and Oromia Administrative Zones, in northern part of Ethiopia) where the altitude range from 1,400 to 2,230 meters above sea-level (Figure 1). Livestock production is extensive system whereby animals of different species and age groups share common grazing land and watering point. The breed composition of the subpopulation is predominantly the local zebu breed. At the time of 
this study, Lumpy Skin Disease re-occurred as an outbreak in these study areas starting from the month of July 2006 after 5-6 years elapse (personal communication with the local veterinary officers).

The second study area was in Oromia Region (Borena and Guji Administrative Zones in southern part of Ethiopia) which have an agro-pastoral farming system with semi arid and sub-humid climate respectively. Altitude range is from 1,590 to 1,740 meters. There was no reported LSD outbreak since 2005 in the area and no vaccination program was put into place for the last 12 months.

\section{Sampling}

The purpose of the sampling design was to obtain different prevalence between the two study populations to hold the Bayesian assumption true where gold standard test is not available. All animals above six months old and both sex groups were subjected to random sampling.

- Population $1\left(\mathrm{P}_{1}\right)$ : in the northern study area, at the district level, the target Peasant Associations (PA) (it is the lowest rural administrative level in Ethiopia which can hold variable number of villages in it) were those with LSD outbreak history. In 7 PA selected from 3 districts, the herds and animals were randomly selected for sample collection. In all the places, the sampling was carried out before the deployment of vaccination to control the outbreak.

- Population $2\left(\mathrm{P}_{2}\right)$ : In southern study area, there was no recent evidence of LSD outbreak. The samples were collected by multistage random sampling technique in 5 PA selected from 2 Districts. At the district level, the PA's were randomly selected and then the herds and the animals too. Thus the study design applied agrees with the complete verification approach (Greiner and Gardner, 2000(b)).

Sample size determination was based on Greiner and Gardner (2000) formula using the prior estimates for sensitivity and specificity of IFAT to be $90 \%$ and $80 \%$ respectively with the desired precision level of 0.05. A total of 463 sera that is 263 sera from the northern area $\left(\mathrm{P}_{1}\right)$ and 200 sera from the southern area $\left(\mathrm{P}_{2}\right)$ were assigned for the study:

\section{Serological Tests}

Blood samples of $5-7 \mathrm{ml}$ were collected in plain vacutainer tube from the jugular vein. The samples were allowed to clot for 2-3 hours at room temperature. Then the serum was extracted by spinning at $2500 \mathrm{rpm}$ and the serum was preserved in $-20^{\circ} \mathrm{C}$ temperature until the test conducted. 
135 The IFAT was used to detect serum antibody against Lumpy Skin Disease. Antibodies of capripox virus

136 can be detected from day 2 after the onset of clinical signs and remain detectable for about 7 months, but

137 a significant rise in titre is usually seen between days 21 up to 42 (Lefèvre et al., 2003; OIE, 2004). The

138 serum samples were processed blindly for the test. The antigen used to detect the serum antibody against

139 lumpy Skin Disease was KS1 (Kenyan Sheep pox virus) strain which is recently proved to have

140 genetically identical with Neethling Virus (Gershon and Black, 1988). The KS1 strain was obtained from

141 CIRAD Laboratory and the Lamb testis cell was infected using $50 \mu 1$ of $100_{\text {TCID50 }}$ viral suspension per

142 well cultured in 96-well flat bottomed tissue-culture grade microtitre plate. The infected monolayer cells

143 were fixed after 48 hours using $80 \%$ acetone. The test serum was diluted in 1/25 in 0,5\% Lamb serum

144 blocking buffer (blocking buffer is to avoid the non specific background reaction) and each serum was

145 tested in duplicate wells. The positive and negative control sera were also included in each plate.

146 Fluorescein isothiocyanate conjugated anti-bovine gamma-globuline ( $\operatorname{IgG}$ ) of Rabbit was diluted in 1/40

147 in 0,5\% Lamb serum blocking buffer and add to each well (Standard Operating Protocol of CIRAD). The

148 plates were read using Zeiss Fluorescent microscope under 40X magnification. The positive test serum

149 appears bright fluorescence foci where the antibody reacted with the virus and the negative serum appears

150 as dark field or dim gray foci.

$151 \quad$ Virus Neutralization Test (VNT)

152 Serial dilution of the test serum was done in $1 / 5,1 / 25,1 / 125,1 / 625$ and 1/3125 dilutions and each serum

153 was tested in duplicate wells. KS1 strain virus in 100 TCID50 per wells constant titration was maintained

154 similar for each well. The Vero cell was used for the test and cultured in 96-well flat bottomed tissue-

155 culture grade microtitre plates (OIE, 2004). The reason for Vero cells preferred was the Vero cells are

156 less sensitive to capripox virus and to reduce the problem of "breakthrough" in which the virus dissociate

157 the antibody binding and relapse to infect the cells (OIE, 2004; Bhanuprakash et al., 2006). The plates

158 were incubated at $37^{\circ} \mathrm{c}, 5 \%$ carbon dioxide $\left(\mathrm{CO}_{2}\right)$ for 9 days. The plates were examined under inverted

159 microscope for the presence of cytopathic effect (CPE) starting from day 4 . The final reading was taken

160 on day 9 and the result was recorded from the highest dilution which inhibited the CPE in both or either

161 of the duplicate wells. The test result was recorded as the reciprocal of the log titration. The interpretation

162 of the result is that the wells with no CPE in 1/25 and more dilutions were considered as positive serum.

163 This indicates that the antibody against the LSD virus has reacted with the KS1 virus and inhibited the

164 growth of the virus not to produce CPE.

\section{Questionnaire Survey}

166 Questionnaire survey included the LSD disease status, potential risk factors and other epidemiological

167 records using questionnaire format which was prepared based on the prior knowledge of the disease in the 
168

169

170

171

172

173

174

175

176

177

178

179

180

181

182

183

184

185

186

187

188

189

190

191

192

193

194

195

196

197

198

199

200

respective sampled sites. The data was analysed by t-test to compare the disease prevalence between the two sampling areas.

\section{Test evaluation}

The laboratory result obtained was cross classified for each population to calculate the test parameters (Table 1). Statistical methods and tools used for evaluation of the test performance under different specific conditions have been discussed (Enoe et al., 2000; Gardner et al., 2000; Johnson et al., 2001; Pouillot et al., 2002; Georgiadis et al., 2003; Orr et al., 2003; Branscum et al., 2005; Kostoulas et al., 2006; Van Schaik et al., 2007).

We applied methods without gold standard to analyse the accuracy since the reference test used was not gold standard in its accuracy. We used comparatively the following methods to analyse our estimates: Maximum Likelihood Estimate (Hui and Walter, 1980) model, conditional independent and dependent Bayesian models (Branscum et al., 2005).

The maximum-likelihood method assumes three conditions: i) the studied population should consist of two subpopulations with different prevalence, ii) in these subpopulations, the test accuracy should be constant and iii) the two tests should be conditionally independent of each other (Hui and Walter, 1980; Pouillot et al., 2002). We used the spreadsheet model of Hui and Walter (1980) from the web site (www.epi.ucdavis.edu/diagnostictests/).

The Se and Sp estimates of IFAT (Se $\mathrm{IFAT}_{\mathrm{F}}$ and $\mathrm{Sp}_{\mathrm{IFAT}}$ ), the Se and Sp of VNT (Se $\mathrm{VNT}_{\mathrm{N}}$ and $\mathrm{Sp} \mathrm{V}_{\mathrm{VNT}}$ ) and the prevalence of the two populations $\left(\mathrm{Pi}_{1}\right.$ and $\left.\mathrm{Pi}_{2}\right)$ were also calculated using Bayesian methods. The study populations have different disease prevalence based on information obtained from the analysis of questionnaire interview data (Table 2) and thus complies with the assumption where gold standard test is not available.

Tests based on similar biological basis might have correlated errors that cause incorrect estimation of sensitivity and specificity (Gardner et al., 2000; Georgiadis et al., 2003; Orr et al., 2003; Branscum et al., 2005). As both IFAT and VNT detect antibodies, it is reasonable to confirm that the tests sensitivity and specificity were indeed conditionally independent on disease status. Then, both conditional independent and dependent Bayesian models for two tests, two populations were applied which allowed us to estimate the Se and Sp conditional correlations ((rhoD) and rhoDc respectively) between the tests and their 95\% probability intervals (95\% PI). We used the model recently reviewed by Branscum et al., (2005) for both 
conditionally independent and dependent assumptions, using Winbugs package (for more details see

202 (Enoe et al., 2000; Georgiadis et al., 2003; Branscum et al., 2005).

203 The assumption of equal accuracy of the tests across subpopulations was checked by considering separate 204 analysis of the two populations (Georgiadis et al., 2003). For each population, the model and prior 205 information used were identical to the model and prior used in the two population case.

\section{Prior Information}

207 In Bayesian analysis prior information are often specified for the unknown parameters either from 208 published papers or experts best guess (Enoe et al., 2000; Branscum et al., 2005). Prior information on 209 sensitivity and specificity of these current tests were obtained from scientists working on capripox 210 research in CIRAD and Institute for Animal Health Pirbright (IAH) laboratory. We could not get any 211 scientific publication data relevant to the determination of the accuracy of tests for Lumpy Skin Disease 212 except the general recommendations on the available diagnostic tests currently in use. The prior 213 information of disease prevalence in the two populations $\left(\mathrm{Pi}_{1}\right.$ and $\left.\mathrm{Pi}_{2}\right)$ were estimated on the basis of the 214 results of the farmers' interviews conducted during the sample collection (Table 2).

The uncertainty of prior information are often modelled through the use of beta distributions (Enoe et al., 217 2000). The modal value of the prior information was transformed to beta distribution model using 218 Betabuster free software from the website (www.epi.ucdavis.edu/diagnostictests/). For conditional 219 independent Bayesian model the prior information for sensitivity of IFAT was mode 0.90 and the transformed beta $(a, b)$ was beta $(130.71,15.41)$ with $5^{\text {th }}$ percentile equals to 0.84 . Prior mode for specificity of IFAT was 0.85 beta $(152.9,27.8)$ with a $5^{\text {th }}$ percentile 0.79 . The sensitivity prior for VNT was mode 0.75 beta $(174.5,58.8), 5^{\text {th }}$ percentile 0.69 and specificity prior mode was 0.95 beta $(99.7,6.2)$ and $5^{\text {th }}$ percentile 0.89 . The beta prior distributions for prevalence of population1 (pi1) and population2 (pi2) were mode 0.24 beta $(118.8,374)$ and $0.06(66,1032)$ respectively and $95^{\text {th }}$ percentiles of 0.28 and 0.075 respectively. For conditional dependent model we used similar prior information as indicated above for $\mathrm{Se}_{\mathrm{VN}}, \mathrm{Sp}_{\mathrm{VN}}$ of VNT, pi1 and pi2. Georgiadis et al., (2003) discussed reparameterization of the second test parameters since prior information is not usually available for the new test during new test validation. However, in this study the prior information obtained from expert's best guess for IFAT sensitivity and specificity were applied instead of reparameterization. Thus we assigned uniform priors for $\lambda_{D}$ and $\gamma_{D}$ a modal value of 0.90 beta $(130.7,15.4)$ with $5^{\text {th }}$ percentile 0.84 and in the same way a uniform prior for

$231 \lambda_{\mathrm{Dc}}$ and $\gamma_{\mathrm{Dc}}$ with a mode of 0.85 beta $(152.9,27.8), 5^{\text {th }}$ percentile of 0.79 (Branscum et al., 2005). 
233 McNemar's chi2-test and the Kappa statistic (k) were used to test the level of agreement between the

234 IFAT and the VNT. McNemar's chi2 was carried out first to test whether there was test bias (i.e. the 235 difference in proportion positive result in each test) (Dohoo et al., 2003). Kappa and its 95\% CI, was used

236 further to measure the degree of agreement between the two tests after taking into account the probability 237 of agreement by chance alone. Strength of agreement based on k was judged according to the following 238 guidelines: $<0.2=$ slight agreement; $0.2-0.4=$ fair; $0.4-0.6=$ moderate; $0.6-0.8=$ substantial; $>0.8=$ 239 almost perfect (Dohoo et al., 2003). The software Intercooler Stata 8.2 (StataCorp LP, College Station, 240 TX) was used for these analyses

241 Statistical and model analysis were computed using STATA 8.0 (Stata Corporation (C) 1984-2003), 242 Winbugs $\AA$, Betabuster and $\mathrm{H} \& \mathrm{~W}$ model Excel spread sheet from online at 243 http://www.epi.ucdavis.edu/diagnostictests/.

\section{Results}

\section{Descriptive Epidemiology}

In both study areas LSD occurrence showed to have seasonal pattern and frequently associated with high moisture climate and high insect population dynamics (Figure 2). About $90 \%$ respondents replied that the disease occurs from July to November which is the season of high moisture and also extends up to December. In the northern study area the LSD outbreak was commenced in July 2006 and continued up to the end of December 2006 which covered a wide extensive area (in four administrative Zones of Amhara Region). Retrospective data analysis of LSD outbreak pattern from year 1999- 2006 also revealed that the temporal distribution graph peaks high at the end of high rainy season (September) and gradually drops down up to the end of December (National disease outbreak report database) (Data not shown).

In the northern study area only 10\% herd owners used their own grazing plots but they shared the same watering point with animals in the surrounding community. The farmers are sedentary in their occupation.

257 However, in the southern part all the community in the peasant Association shares the same grazing land 258 and watering point. Moreover, about $50 \%$ of the herd owners in the southern part responded that they have transhumant mode of life in which they move their herd seasonally to other grazing places in search of better feed and water for their animals.

\section{Maximum Likelihood Estimates}

262 The Maximum Likelihood Estimates (MLE) of Hui and Walter model highly over estimated the Se $\mathrm{e}_{\mathrm{IFAT}}$, $263 \mathrm{Se}_{\mathrm{VN}}$ and pil as compared to the estimates of Bayesian models. The point estimates of MLE were not 
included in the $95 \%$ probability interval ranges of the Bayesian posterior inference (Table 3 ). However, specificity of both tests and pi2 were not significantly different from the estimates of Bayesian models in which the estimates were in the $95 \%$ probability interval range of the respective parameters.

\section{Bayesian Conditional Independent and Dependent Models}

The posterior inferences obtained by conditional independent and dependent Bayesian models were consistently similar in all estimated parameters. The analysis of conditional correlation between the two tests showed the conditional dependence between the tests were significantly minimum, which was less than 0.1 for both sensitivity (rhoD) and specificity (rhoDc) (Table 3). The 95\% probability interval of conditional correlation estimate for sensitivity and specificity included zero in which the hypothesis for the conditional dependence could be rejected (Gardner et al., 2000).

The $\mathrm{Sp}_{\mathrm{VN}}$ obtained from Bayesian estimates was nearly perfect for LSD diagnosis which is in the contrary to its low sensitivity estimate $0.78(0.74-0.83)$. In our finding, the Se $\mathrm{IFAT}_{\text {was }}$ found to be high at 0.92 (0.89- 0.95) as expected. Similarly the specificity was also fairly good at $0.88(0.85-0.91)$ as it was considered to have lower specificity due to the possible cross reactions of parapox and orthopox virus with capripox virus.

\section{The Se and Sp estimates calculated separately for each population showed that one-population analysis} were consistent with the second population analysis and with the two-population case, indicating that our assumption of similar accuracy of the tests across the two populations was valid (Table 4). The precision of point estimates for sensitivity and specificity of both tests were within the range of 0.03 and 0.01 respectively.

\section{Analysis of Bayesian Model Sensitivity}

We used three sets of prior information for model sensitivity analysis (Table 3). (1.) Non informative priors for all parameters of the two tests showed that the posterior inferences for $\mathrm{Se}_{\mathrm{IFAT}}$ and $\mathrm{Se}_{\mathrm{VN}}$ were largely over-estimated while the rest parameters were remained almost similar estimation (result not shown). (2.) Using informative priors for the two prevalences only, the median estimate for $\mathrm{Se}_{\mathrm{VN}}$ was still over-estimated although its interval estimate included the true value and the remaining estimates were seemed not significantly affected (Table 3 Model 5). (3.) Additional model sensitivity analysis using informative priors for pi1, pi2, $\mathrm{Se}_{\mathrm{VN}}$ and $\mathrm{Sp}_{\mathrm{VN}}$ showed that the model estimates were not distinctly different from the analysis obtained using prior information for all parameters (Table 3 model 4). But the conditional correlation for specificity resulted significant test dependence. The model converged fairly for 
296 all parameters in model 4 and 5 (Table 3) prior information than when non informative priors were

297 assigned for all the parameters.

298 The convergence of the Bayesian models were analysed by observing kernel density and trace plots of the

299 model visually and the plots stabilized consistently for all the parameters. The first 5000 iterations were

300 discarded as burn-in phase and the posterior inferences were based on 100,000 iterations.

301 Autocorrelations were also checked and there was no meaningful autocorrelation observed.

\section{Test Agreement}

303 The difference in the proportion positive tests calculated for McNemar's $X^{2}$ test showed significant 304 difference (McNemar's chi2 $=33.62, \mathrm{p}<0.000$ ) between the tests. Test agreement between the two tests 305 using Kappa statistics was Kappa $=0.70(0.61-0.78)$ showing that the two tests have substantial 306 agreement according to the interpretation of Kappa result (Dohoo et al., 2003).

307 Discussion

308 In both study areas we noted that extensive livestock production system allows maximum chance for 309 different herd mixing during utilization of communal grazing lands and watering points. Under this 310 prevailing system it is likely to speculate that the introduction and spread of LSD infection could have 311 favourable environment. Uncontrolled cattle movements due to trade, pastoralism, vector insects 312 population and dynamic, wet climate which favours insect multiplications and other reasons of cattle 313 movement from place to place could render potential risk factors for the transmission of the disease from 314 herd to herd and from place to place as it is true for other infectious disease too (Toma et al., 1999).

315 Seasonal characteristics of LSD occurrence implies that the transmission of the disease might linked with 316 the optimum season for the development of vector insects population (Kitching and Mellor, 1986; 317 Chihota et al., 2001, 2003). However, there are still little hard evidences for the specific insect vectors 318 incriminated in the transmission of LDSV and may deserve further study to elaborate the principal 319 vectors.

320 The immune response against LSD involves predominantly cell mediated immune response and the 321 humoral immune system would last short period of life mostly for 7 months (Lefèvre et al., 2003; OIE, 322 2004). Hence studies based on serological detection of the disease should take into consideration the short 323 lifespan of detectable antibody in the blood. For sample collection, we selected the natural infected 324 population under active disease outbreak situation as P1 and the other population with unknown disease 325 status but which could have had exposure to the infection as P2. This approach has greatly enabled to get 

significantly different prevalence between the two sub-populations which might be the ideal assumption for epidemiological approach of diagnostic test evaluation for Lumpy Skin Disease.

An optimum consideration was taken during the laboratory techniques to limit the possible cross reaction of parapox and orthopox virus with LSD virus and the information obtained through epidemiological disease investigation records was also used to understand the clinical disease situation in the study population. The members of Capripox virus Genus are antigenically very close related, which makes not possible to distinguish them by serological tests (Davies and Otema, 1981). However, capripox virus is highly host-specific under natural environment (Capstick and Coackley, 1961) and there has not been recorded incidence of Lumpy Skin Disease occurrence from sheep pox or goat pox disease outbreak. This has been clearly evidenced that the Republic of South Africa had LSD but having huge number of sheep and goats there was no incidence of Sheep and goat pox disease (Capstick and Coackley, 1961). In Middle East countries where sheep pox is endemic, LSD incidence has never been reported except the case reported in Israel and eradicated soon in 1989 (Yeruham et al., 1995). In Kenya sheep was found infected where the first outbreak of LSD occurred, which was the first in kind (Davies, 1991). But in an other study this Kenyan sheep and goat pox strain was proved to have more genetic similarity to Neethling virus than classical sheep pox or goat pox virus which maybe due to some genetic mutation enabled for adaptation to cattle (Gershon and Black, 1988). In our study sheep pox did not occur concurrently with LSD in the outbreak areas and it had never been noted to occur as a multi-host outbreak in the same place unless they coincided due to accidental overlap (personal communication with vet officers in study area).

Cross reaction of cowpox virus was observed to occur with LSD virus at lower dilution $(\leq 1 / 8)($ Davies and Otema, 1981). But we diluted the test sera for IFAT at 1/25 concentration that might help us to reduce the possibility of cross reacting globulins and non specific background reactions. As a result it might have contributed to get better specificity test result which was $0.88(0.85-0.91)$. However, the cross reaction of cowpox with LSD virus observed in IFAT had not been demonstrated in VNT (Davies and Otema, 1981) which is in congruent with the high specificity estimated for VNT it our finding.

Maximum likelihood estimate (MLE) over-estimated three parameters out of six which did not fall in the 95\% probability interval of the Bayesian estimates. The 95\% confidence interval of MLE was also wider than the interval estimates of Bayesian models. The variation in the point estimates and the wider range for the interval estimates might reveal the uncertainty of MLE that assumes large sample size. Thus the method might not be applicable in our case due to small sample size (Enoe et al., 2000; Orr et al., 2003).

As both tests measure the same biological factor we expected certain degree of dependence between the two tests. However, both conditional independent and dependent models had similar estimates for all 
parameters which indicated that the two tests are conditionally independent. The $95 \%$ probability interval of conditional correlation estimates were clustered around zero for both sensitivity and specificity which showed that the dependence of the tests were not significant (Georgiadis et al., 2003). This implies also the two tests could be used in series and parallel test combinations for a maximum test efficiency (Gardner et al., 2000; Greiner and Gardner, 2000; Dohoo et al., 2003). Although the estimates we found from conditional independent and dependent models did not vary, we preferred to use the conditional dependent model for discussion to elucidate the information regarding the magnitude of test dependence (Enoe et al., 2000; Gardner et al., 2000; Branscum et al., 2005).

The posterior inferences estimated across the two populations separately and jointly showed insignificant difference (Table 4). The point estimates of each parameter obtained from separate analysis of each population lies within the $95 \%$ probability interval ranges of respective parameter in the combined population analysis. This supported the model assumption for similar test accuracy in the two populations. The slight variation observed in the precision of point estimates of $\mathrm{Se}_{\mathrm{IFAT}}$ and $\mathrm{Se}_{\mathrm{VN}}$ in population 2 might be due to small sample size coupled with lower disease prevalence in this population. The results could also reveal that Bayesian method has superior approximation to give reasonable posterior inference even under a small sample size condition (Branscum et al., 2005)..

In the analysis of model sensitivity using non informative priors for all the parameters, we found that the $\mathrm{Se}_{\mathrm{IFAT}}$ and $\mathrm{Se}_{\mathrm{VN}}$ estimates were unlikely over estimated which might be due to non-identifiable model where the unknown parameters are greater than the degree of freedom. Whereas the posterior median obtained by using informative prior for pi1, pi2, $\mathrm{Se}_{\mathrm{VN}}$ and $\mathrm{Sp}_{\mathrm{VN}}$ (Table 3, model 4) and for pi1, pi2 (Table 3 , model 5) resulted better estimation except the overestimated value of $\mathrm{Se}_{\mathrm{VN}}$ in the latter model analysis. This indicates that the availability of prior information for the prevalences and the accuracy of one test would be necessary to get optimum posterior inferences (Georgiadis et al., 2003; Branscum et al., 2005). In general we can conclude that the posterior inferences of the Bayesian models did not vary distinctly for the changes in the prior information which indicates that the models were not significantly influenced by the prior information.

The substantial agreement between the tests observed from kappa statistics was not supported by McNemar's $\mathrm{X}^{2}$ test. The difference in the proportion positive test results was significantly different for the two tests $($ McNemar's chi2 $=33.62, \mathrm{p}<0.000)$. This significant difference in the proportion of positive test results might be explained by the low sensitivity in Virus neutralization test and a minimum conditional dependence between the two tests (Dohoo et al., 2003). But in reality this empirical difference might not justify the presence of a test bias from a biological point of view since it reflects the existence of significant difference in the sensitivity estimates of the two tests. 


\section{Conclusion}

393 In this study we observed that the accuracy of Indirect Fluorescent Antibody test was fairly good in both

394 sensitivity and specificity parameters indicating that it can be used for LSD diagnosis and screening with 395 low misclassification. Its capacity to run large number of samples per plate (45 samples per plate) could 396 be also taken as an advantage to use for large epidemiological studies of LSD. However, to undertake 397 similar epidemiological study on sheep pox and goat pox, we suggest further evaluation study to 398 determine the accuracy of these tests for sheep pox and goat pox diseases. Test accuracy my vary 399 according to the target population of concern and extrapolating directly the result of current study on LSD 400 might lead to unwise conclusion for sheep pox and goat pox diseases.

401 The conditional correlation estimates between the two tests revealed that the tests are conditionally 402 independent on the disease status of the animal. This implies that the two tests could be used especially in 403 parallel test combinations with maximum sensitivity efficiency.

404 The drawback in using IFAT is that the test requires longer time and may be more costly as compared to 405 ELISA technique. We recommend more efforts and studies should be done towards the development and 406 validation of ELISA test which may outmatch the limitations of the currently in-use diagnostic and 407 screening tools. 
408

409

410

411

412

413

414

415

416

417

418

419

420

421

422

423

424

425

426

427

428

429

430

431

432

433

434

435

436

437

438

\section{Acknowledgements}

This work was financed by the General Directorate for Development and International Cooperation, French Ministry of Foreign Affairs, French Embassy in Ethiopia through PSF No 2003-24 LABOVET project. I would like to thank for the financial support to undertake this study and the fellowship program.

I am highly grateful to Dr Emmanuel Albina for his technical advises and managing the transport of the samples from Ethiopia to CIRAD. I am indebted to Adam Diallo, Cathrine Sossah and Guillaume Gerbier for their technical advises. I am grateful to all Staffs of Virology Research Laboratory in CIRAD for their unreserved technical assistances and cooperative spirit through all my laboratory works and to Sebeta NAHRC colleagues who helped me during the field work in Ethiopia.

\section{References}

Alexander, R.A., Plowright, W., and, Haig, D.A., 1957. Cytopathogenic Agents Associated with Lumpy Skin Disease of Cattle. Bull. Epiz. Dis. Afr. 5, 489-492.

Ali, A.A., Esmat, M., Attia, H., Selim, A., Abdel-Hamid, Y.M., 1990. Clinical and pathological studies of lumpy skin disease in Egypt. Vet. Rec. 127, 549-550.

Bhanuprakash, V., Indrani, B.K., Hosamani, M., Singh, R.K., 2006. The current status of sheep pox disease. Comp. Immunol. Microbiol. Infect. Dis. 29, 27-60.

Biteau-Coroller, F., Gerbier, G., Stark, K.D.C., Grillet, C., Albina, E., Zientara, S.a., Roger, F., 2006. Performance Evaluation of a Competitive ELISA test Used for Bluetongue Antibody Detection in France, a Recently Infected Area. Vet. Microbiol. 118, 57-66.

Branscum, A.J., Gardner, I.A., and , Johnson, W.O., 2005. Estimation of diagnostic-test sensitivity and specificity through Bayesian modeling. Prev. Vet. Med. 68, 145-163.

Capstick, P.B., Coackley, W., 1961. Protection of Cattle Against Lumpy Skin Disease, 1. Trails with a Vaccine Against Neethling Virus Type Infection. Res. Vet. Sci. 2, 362-368.

Chihota, C.M., Rennie, L.F., Kitching, R.P., Mellor, P.S., 2003. Attempted mechanical transmission of lumpy skin disease virus by biting insects. Med Vet Entomol 17, 294-300.

Chihota, C.M., Rennie, L.F., Kitching, R.P., Mellor, P.S., 2001. Mechanical transmission of lumpy skin disease virus by Aedes aegypti (Diptera: Culicidae). Epidemiol Infect 126, 317-321.

Davies, F.G., 1982. Observations on the epidemiology of lumpy skin disease in Kenya. J. Hyg. (Lond) 88, 95-102. 
Davies, F.G., 1991. Lumpy skin disease of cattle: a growing problem in Africa and the Near East. World Animal Review 68, 37-42.

Davies, F.G.a., Otema, C., 1981. Relationships of Capripox Viruses found in Kenya With two Middle Eastern Strains and Some Orthopox Viruses. Res. Vet. Sci. 31, 253-255.

Dohoo, I., Martin, W.a., Stryhn, H., 2003. Screening and diagnostics tests, In: Veterinary epidemiologic research. AVC Inc., Charlottetown, Prince Edward Island, Canada, pp. 85-120. pp.

Enoe, C., Andersen, S., Sorensen, V., Willeberg, P., 2001. Estimation of sensitivity, specificity and predictive values of two serologic tests for the detection of antibodies against Actinobacillus pleuropneumoniae serotype 2 in the absence of a reference test (gold standard). Prev. Vet. Med. 51, 227-243.

Enoe, C., Georgiadis, M.P.a., Johnson, W.O., 2000. Estimation of sensitivity and specificity of diagnostic tests and disease prevalence when the true disease state is unknown. Prev. Vet. Med. 45, 61-81.

Gardner, I.A., Stryhn, H., Lind, P.a., Collins, M.T., 2000. Conditional Dependence Between Tests Affects the Diagnosis and Surveillance of Animal Diseases. Prev. Vet. Med. 45, 107-122.

Georgiadis, M.P., W. O. Johnson, and, I.A.G., R. Singh, 2003. Correlation-adjusted Estimation of Sensitivity and Specificity of Two Diagnostic Tests. Appl. Statist. 52, 63-76.

Gershon, P.D., and, Black, D.N., 1988. A Comparison of the Genomes of Capripox Isolates of Sheep, Goat and Cattle. Virology 164, 341-349.

Greiner, M., and, Gardner, I.A., 2000(b). Epidemiologic issues in the validation of veterinary diagnostic tests. Prev. Vet. Med. 45, 3-22.

Greiner, M., Gardner, I.A., 2000. Epidemiologic issues in the validation of veterinary diagnostic tests. Prev. Vet. Med. 45, 3-22.

Greiner, M.a., Gardner, I.A., 2000(a). Application of Diagnostic Tests in Veterinary Epidemiologic Studies. Prev. Vet. Med. 45, 43-59.

Heine, H.G., Stevens, M.P., Foord, A.J., Boyle, D.B., 1999. A capripoxvirus detection PCR and antibody ELISA based on the major antigen P32, the homolog of the vaccinia virus H3L gene. J. Immunol. Methods 227, 187-196.

Hui, S.L., Walter, S.D., 1980. Estimating the Error Rates of Diagnostic Tests. Biometrics 36, 167- 171. Johnson, W.O., Gastwirth, J.L.a., Pearson, L.M., 2001. Screening without a "Gold Standard": The HuiWalter Paradigm Revisited. Am. J. Epidemiol. 153, 921-924.

Kitching, R.P.a., Mellor, P.S., 1986. Insect Transmission of Capripox Viruses. Res Vet Sci 40, 255-258. Kostoulas, P., Leontides, L., Enoe, C., Billinis, C., Florou, M.a., Sofia, M., 2006. Bayesian Estimation of Sensitivity and Specificity of Serum ELISA and Faecal Culture for Diagnosis of Paratuberculosis ic Greek Diary Sheep and Goats. Prev. Vet. Med. 76, 56-73. 
473

474

475

476

477

478

479

480

481

482

483

484

485

486

487

488

489

490

491

492

493

494

495

496

497

498

499

500

501

502

503

504

505

506

507

Lefèvre, P.C., Blancou, J., Chermette, R., 2003. Dermatose Nodulaire Contagieuse, Vol 1. LAVOISIER, Londres- Paris- New York, 429-441 pp.

Mebratu, G.Y., Kassa, B., Fikre, Y., Berhanu, B., 1984. Observation on the outbreak of lumpy skin disease in Ethiopia. Rev. Elev. Med. Vet. Pays. Trop. 37, 395-399.

OIE, 2004. Manual of Diagnostic Tests and Vaccines for Terrestrial Animals. OIE Part 2, 1-17.

Orr, K.A., O'Reilly, K.L., and, Scholl, D.T., 2003. Estimation of Sensitivity and Specificity of Two Diagnostic Tests for Bovine Immunodeficiency Virus Using Bayesian Techniques. Prev. Vet. Med. 61, 79-89.

Pouillot, R., Gerbier, G.a., Gardner, I.A., 2002. "TAGS" a Program for the Evaluation of Test Accuracy in the Absence of a Gold Standard. Prev. Vet. Med. 53, 67-81.

Toma, B., Dufour, B., Sanaa, M., Bénet, J.J., Moutou, F., Louzà, A., Ellis, P., 1999. Applied Veterinary Epidemiology and the Control of Disease in Populations. AEEMA.

Van Schaik, G., Haro, F., Mella, A.a., Kruze, J., 2007. Bayesian Analysis to Validate a Cmmerial ELISA to Detect Paratubetculosis in Diary Herds of Southern Chile. Prev. Vet. Med. 79, 59-69.

Yeruham, I., Nir, O., Braverman, Y., Davidson, M., Grinstein, H., Haymovitch, M., Zamir, O., 1995. Spread of lumpy skin disease in Israeli dairy herds. Vet. Rec. 137, 91-93. 


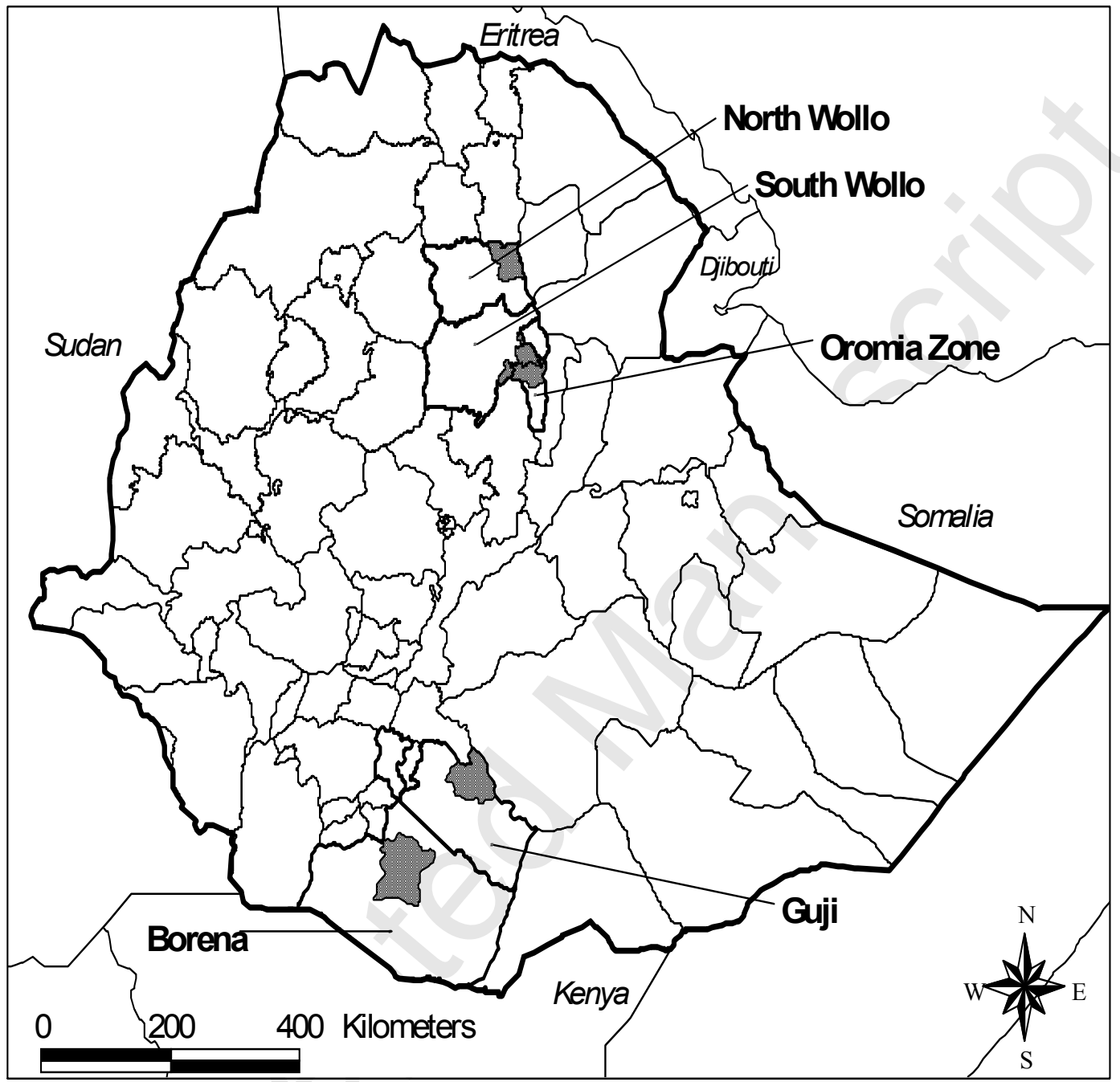

Figure 1: Map of Ethiopia with the locations of the study areas (shaded areas) (Source: International Food Policy Research Institute, Atlas of the Ethiopian Rural Economy, 2006) 


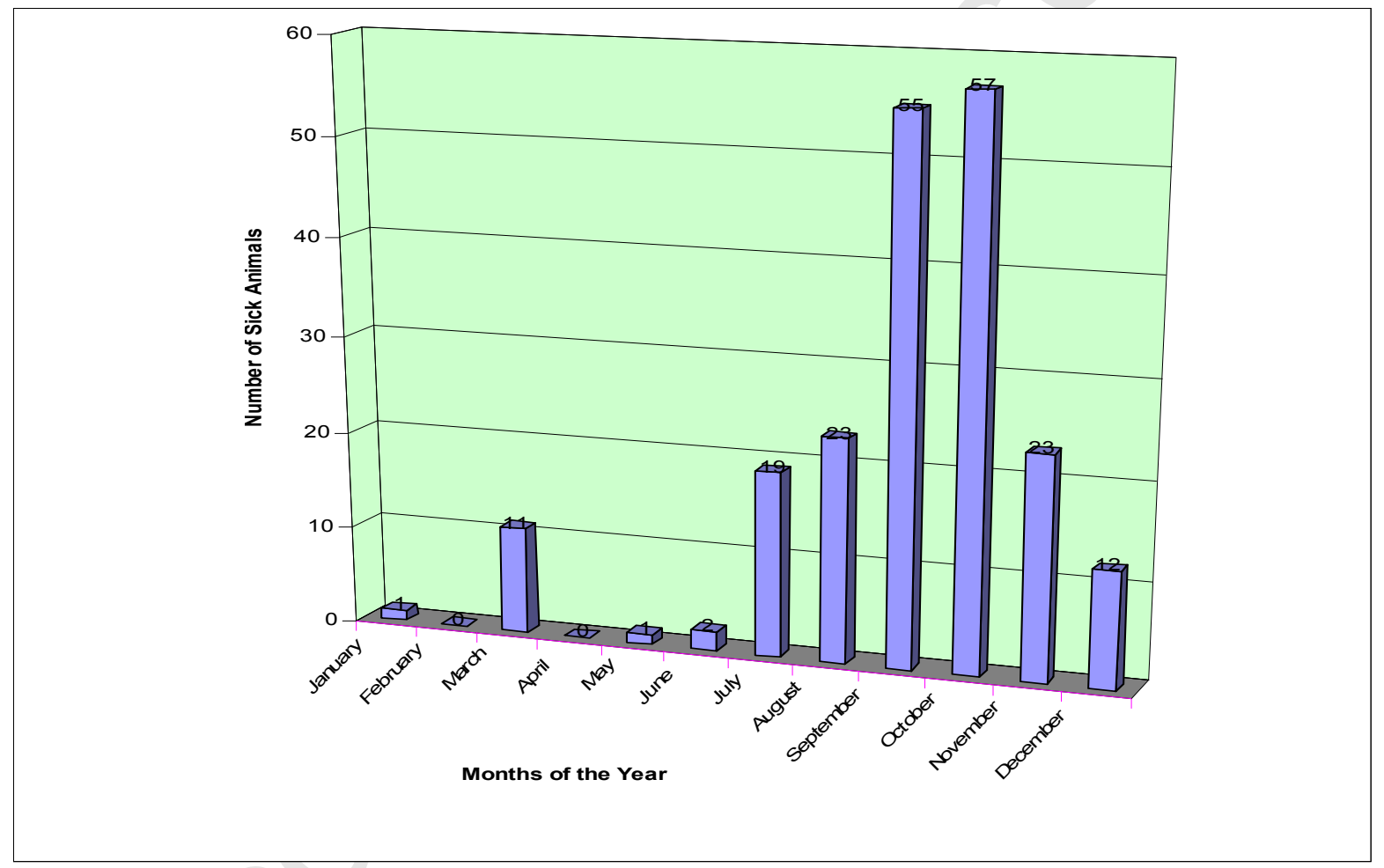

Figure 1: Seasonal occurrence of LSD in the studied areas based on the data from questionnaire interview 
1 Table 1: Cross classification of the IFAT and VNT results from serum samples in two cattle populations

2 with expected high prevalence in $\mathrm{P}_{1}$ and low prevalence in $\mathrm{P}_{2}$

3

\begin{tabular}{|c|c|c|c|c|c|c|}
\hline & \multicolumn{5}{|c|}{ Virus neutralization test } & \multirow{3}{*}{ Total } \\
\hline & \multicolumn{3}{|c|}{$\mathrm{P} 1$} & \multicolumn{2}{|l|}{$\mathrm{P} 2$} & \\
\hline & & + & - & + & - & \\
\hline \multirow[t]{2}{*}{ IFAT } & + & 82 & 29 & 12 & 20 & 143 \\
\hline & - & 3 & 149 & 3 & 165 & 320 \\
\hline Total & & 85 & 178 & 15 & 185 & 463 \\
\hline
\end{tabular}

4 
5 Table 2: Lumpy Skin Disease prevalence estimation based on farmers' opinions collected in the two study 6 areas.

7

\begin{tabular}{lccr}
\hline Studied Population & Northern study area & Southern study area & Total \\
\hline Number of investigated herds & 99 & 53 & 152 \\
Number of sampled animals & 615 & 1097 & 1712 \\
Number of LSD diseased cattle & 150 & 66 & 216 \\
Estimated Prevalence & $24.4 \%(\mathrm{CI}: 21,27.8 \%)$ & $6 \%(\mathrm{CI}: 4.6,7.4 \%)^{* *}$ & \\
LSD Mortality & $2.8 \%(\mathrm{CI}: 1.3,4.3 \%)$ & $1.8 \%(\mathrm{CI}: 1,2.6 \%)$ & \\
\hline
\end{tabular}

$8 * * *$ Significantly different at $\mathrm{p}<0.05$

9 Note: Herd in this context is defined as cattle possessed by one farmer or a group of relatives which are 10 managed together in a similar manner.

11

12 
14 Table 3: The sensitivity and specificity estimates of Indirect Fluorescent Antibody Test (IFAT) (Se $\mathrm{IFAT}_{\text {and }} \mathrm{Sp}_{\mathrm{IFAT}}$ ) and Virus Neutralization Test (VNT) (Se $\mathrm{VNNT}_{\mathrm{V}}$ 15 and $\mathrm{Sp}_{\mathrm{VNT}}$ ), for the detection of antibodies against Lumpy Skin Disease in serum samples by the Hui and Walter and the Bayesian models with prevalence estimates 16 for the two study populations and conditional correlation estimates.

\begin{tabular}{|c|c|c|c|c|c|}
\hline \multirow[b]{2}{*}{ Parameters } & \multicolumn{5}{|c|}{ Median (\%) and (95\% Probability interval) } \\
\hline & Model $1^{\mathrm{a}}$ & Model $2^{\mathrm{b}, \mathrm{d}}$ & Model $3^{\mathrm{c}, \mathrm{d}}$ & Model $4^{\mathrm{c}, \mathrm{e}}$ & Model $5^{\mathrm{c}, \mathrm{f}}$ \\
\hline $\mathrm{Pi}_{1}$ & $0.36(0,27-0,44)$ & $0.28(0.25-0.32)$ & $0.28(0.25-0.32)$ & $0.27(0.24-0.31)$ & $0.265(0.23-0.30)$ \\
\hline $\mathrm{Pi}_{2}$ & $0.07(0.03-0.10)$ & $0.06(0.05-0.08)$ & $0.06(0.048-0.075)$ & $0.058(0.045-0.07)$ & $0.058(0.05-0.07)$ \\
\hline $\mathrm{Se}_{\text {IFAT }}$ & $0.99(0.93-1.0)$ & $0.93(0.89-0.96)$ & $0.92(0.89-0.95)$ & $0.89(0.75-0.98)$ & $0.95(0.84-0.99)$ \\
\hline $\mathrm{Se}_{\mathrm{VN}}$ & $0.87(0.72-1.0)$ & $0.79(0.74-0.83)$ & $0.78(0.74-0.83)$ & $0.77(0.71-0.82)$ & $0.94(0.79-0.99)$ \\
\hline $\mathrm{Sp}_{\text {IFAT }}$ & $0.90(0.85-0.95)$ & $0.88(0.85-0.91)$ & $0.88(0.85-0.91)$ & $0.85(0.8-0.90)$ & $0.85(0.80-0.89)$ \\
\hline $\mathrm{Sp}_{\mathrm{VN}}$ & $0.98(0.96-1.0)$ & $0.97(0.96-0.99)$ & $0.97(0.95-0.99)$ & $0.94(0.91-0.97)$ & $0.96(0.91-0.99)$ \\
\hline RhoD & & & $0.052(-0.03-0.15)$ & $0.46(-0.04-0.90)$ & $0.38(-0.016-0.88)$ \\
\hline RhoDc & & & $0.019(-0.01-0.06)$ & $0.43(0.17-0.61)$ & $0.28(-0.015-0.55)$ \\
\hline
\end{tabular}

$18{ }^{a}$ Model 1 is a Maximum Likelihood Estimate (MLE) based on the Hui and Walter (1980) model.

$19{ }^{\mathrm{b}}$ Model 2 is based on the assumption of conditional independent model.

$20{ }^{\mathrm{c}}$ Models 3, 4 and 5 are based on the assumption of conditional dependent model.

$21{ }^{d}$ Models 2 and 3 used the following priors: Se $\mathrm{IFAT}_{\text {IF }}$ 0.90, $\beta(130.7,15.4)$; $\operatorname{Sp}_{\mathrm{IFAT}}$ : 0.85, $\beta(152.9,27.8) ; \mathrm{Se}_{\mathrm{VN}}: 0.75, \beta(174.5,58.8)$;

$22 \quad \mathrm{Sp}_{\mathrm{VN}}: 0.95, \beta(99.7,6.2) ; \mathrm{Pi}_{1}: 0.24, \beta(118.8,374) ; \mathrm{Pi}_{2}: 0.06, \beta(66,1032)$

23 e Model 4 used non-informative priors $\beta(1 ; 1)$ for $\mathrm{se}_{\mathrm{IFAT}}$, $\mathrm{sp}_{\mathrm{IFAT}}$, the other parameters are the same priors as in models 2 and 3.

$24 \mathrm{f}^{\mathrm{f}}$ Model 5 used non-informative priors $\beta(1 ; 1)$ for $\mathrm{se}_{\mathrm{IFAT}}, \mathrm{sp}_{\mathrm{IFAT}}, \mathrm{se}_{\mathrm{VN}}, \mathrm{sp}_{\mathrm{VN}}$ and the same priors as in model 2 and 3 for Pi1 and Pi2. 
26 Table 4: Estimates of one population-two tests and combined two populations-two tests Bayesian

27 Analysis for the evaluation of test accuracy similarity across the two populations.

28

\begin{tabular}{lclc}
\hline Parameters & \multicolumn{1}{c}{$\mathrm{P}_{1}$} & \multicolumn{1}{c}{$\mathrm{P}_{2}$} & $\mathrm{P}_{1}+\mathrm{P}_{2}$ \\
\hline $\mathrm{Se}_{\mathrm{IFAT}}$ & $0.93(0.89-0.96)$ & $0.90(0.85-0.94)$ & $0.92(0.89-0.95)$ \\
$\mathrm{Se}_{\mathrm{VNT}}$ & $0.78(0.74-0.83)$ & $0.75(0.70-0.80)$ & $0.78(0.74-0.83)$ \\
$\mathrm{Sp}_{\mathrm{IFAT}}$ & $0.86(0.82-0.90)$ & $0.87(0.84-0.91)$ & $0.88(0.85-0.91)$ \\
$\mathrm{Sp}_{\mathrm{VNT}}$ & $0.97(0.94-0.97)$ & $0.97(0.94-0.98)$ & $0.97(0.95-0.99)$ \\
$\mathrm{Pi}$ & $0.28(0.25-0.32)$ & $0.061(0.049-0.076)$ & \\
\hline
\end{tabular}

29

In parenthesis, $95 \%$ probability interval

30

31 